\title{
RANCANG BANGUN SISTEM INFORMASI PUBLIK BERBASIS WEB (STUDI KASUS : DESA DURIAN KECAMATAN PADANG CERMIN KABUPATEN PESAWARAN)
}

\author{
Mia Melinda ${ }^{1)}$, Rohmat Indra Borman ${ }^{2)}$, Erliyan Redy Susanto ${ }^{3)}$ \\ 1), 2), 3) Fakultas Teknik dan Ilmu Komputer, Universitas Teknokrat Indonesia \\ Jl. H.ZA Pagaralam, No 9-11, Labuhanratu,Bandarlampung \\ Email : 1, rohmat_indra@teknokrat.ac.id ${ }^{1)}$,erliyan.redys@teknokrat.ac.id ${ }^{3)}$
}

\begin{abstract}
Abstrak
Pelayanan publik pada dasarnya adalah upaya sebuah organisasi baik langsung maupun tidak langsung untuk memenuhi kebutuhan dengan layanan yang baik. Informasi yang dapat diakses oleh publik dibutuhkan informasi yang cepat dan tepat waktu, tidak terkecuali pelayanan informasi di desa. Di kantor desa Durian Kecamatan Padang cermin Kabupaten Pesawaran mempunyai banyak informasi publik diantaranya mengenai kegiatan desa, bantuan atau hanya sekedar memberikan informasi kepada masyarakat. Salah satu dari pelayanan publik yang bersifat pembuatan surat salah satu contohnya penerbitan (SKTM) Surat Keterangan Tidak Mampu. Proses dalam pelayanan surat-surat yang dibutuhkan oleh masyarakat melalui proses yang panjang. Hal ini dapat membuat proses untuk mengurus surat-surat tersebut terasa berat oleh masyarakat. Selain itu informasi desa hanya melalui mading dan informasi melalui ketua RT. Penelitian ini menghasilkan sebuah sistem informasi publik berbasis web yang dapat mepermudah masyarakat untuk mendapatkan informasi yang dibutuhkan sehingga dapat meningkatkan pelayanan kepada masyarakat.
\end{abstract}

Kata kunci: desa, informasi, publik, sistem, web.

\section{Pendahuluan}

Dalam Pasal 34 Undang - Undang Dasar 1945 Negara Republik Indonesia menyebutkan bahwa fakir miskin dan anak - anak terlantar dipelihara oleh negara, negara mengembangkan sistem jaminan sosial bagi seluruh rakyat dan memberdayakan masyarakat yang lemah dan tidak mampu sesuai dengan martabat kemanusiaan, negara bertanggung jawab atas fasilitas pelayanan kesehatan dan fasilitas pelayanan umum yang layak, ketentuan lebih lanjut mengenai pelaksanaan pasal ini diatur dalam undang - undang. Menurut penjelasan pasal tersebut terlihat bahwa dalam kehidupan berbangsa dan bernegara, kemakmuran masyarakatlah yang paling diutamakan, bukan kemakmuran seorang saja. Pelayanan pada dasarnya dapat diartikan sebagai aktivitas seseorang, sekelompok atau organisasi baik langsung maupun tidak langsung untuk memenuhi kebutuhan (Pasolong, 2010). Penyelenggaraan urusan pemerintah dibagi dalam kriteria eksternalitas, akuntabilitas, dan efisiensi dengan memerhatikan keserasian hubungan antar susunan pemerintah, sebagai suatu sistem antara hubungan kewenangan pemerintah, kewenangan pemerintah daerah provinsi, dan pemerintah kabupaten/kota, atau antar pemerintahan daerah yang saling terkait, tergantung, dan sinergis, yang bertujuan memudahkan aparat pemerintah dalam melayani masyarakat.

Di kantor desa Durian Kecamatan Padang cermin Kabupaten Pesawaran mempunyai banyak informasi publik mengenai kegiatan desa, bantuan atau hanya sekedar memberikan informasi kepadamasyarakatsekitar. Salah satu dari pelayanan publik tersebut adalah penerbitan (SKTM) Surat Keterangan Tidak Mampu yang dikeluarkan oleh Kepala Desa dan kemudian yang diketahui oleh Camat kepada warga miskin atau kurang mampu yang mengajukan surat permohonan tersebut. Selain pengurusan surat, masyarakat juga membutuhkan informasi tentang desa dan pengumuman-pengumuman penting yang harus dapat diperoleh masyarakat secara $u p$ to date.

Proses dalam pelayanan surat-surat yang dibutuhkan oleh masyarakat melalui proses yang panjang. Harus mengurus surat pengantar dari RT dan kemudian diteruskan ke kantor Desa. Hal ini dapat membuat proses untuk mengurus surat-surat tersebut terasa berat oleh masyarakat. Sedangkan untuk informasi desa dan pengumuman penting yang berhubungan dengan program-program desa hanya melalui mading dan informasi melalui ketua RT. Untuk meningkatkan pelayanan kepada masyarakat dalam pembuatan surat dan informasi publik yang lain maka dibutuhkan sistem informasi berbasis website yang dapat mepermudah masyarakat untuk mendapatkan informasinya. Sistem informasi terdiri dari satuan komponen yang saling berhubungan yang mengumpulkan, memproses, menyimpan, dan mendistribusikan informasi untuk mendukung pengambilan keputusan dalam suatu organsasi (Rahmawati, 2013). Peranan sistem informasi adalah membantu mengendalikan dan mengorganisasikan aktivitas aktivitas dari sub sistem sub sistem dalam organisasi sehingga membantu organisasi tersebut dalam mencapai tujuannya (Lipursari, 2012). 


\section{Pembahasan}

Untuk membangun sistem informasi publik maka dibutuhkan tahapan penelitian, berikut ini adalah tahapan penelitian yang dilakukan :

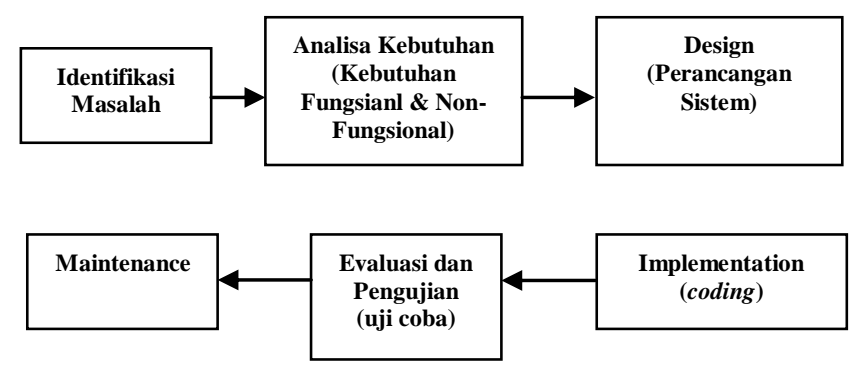

Gambar 1. Tahapan Penelitian

\subsection{Identifikasi Masalah}

Untuk membangun sistem informasi maka langka pertama yang dilakukan adalah identifikasi masalah untuk mengetahui permasalahan yang timbul. Dari pengumpulan data telah dilakukan permasalahan yang terjadi pada desa durian kecamatan padang cermin kabupaten pesawaran yaitu :

1. Belum adanya sistem yang berbasis web dalam penyebaran informasi yang berkaitan dengan kegiatan desa dan pembuatan surat keterangan tidak mampu.

2. Masyarakat kurang informasi tentang pengumuman dan informasi penting desa dan kesulitan dalam pembuatan surat-surat yang dibutuhkan.

\subsection{Analsis Kebutuhan}

Setelah permasalaha diidentifikas, maka langkah selanjutnya adalah menetapkan kebbutuhan atau analisa kebutuhan. Analisis kebutuhan perangkat lunak menentukan apa yang harus dilakukan sistem dan mendefinisikan batasan batasan operasi dan implementasinya agar dapat mengomunikasikan secara tepat semua fungsi yang diberikan (Sommervile, 2011). Analisis kebutuhan perangkat lunak dapat dikatakan sebagai proses mendapatkan informasi, model, spesifikasi sistem yang diinginkan pengguna (Simarmata, 2010). Analisis kebutuhan sistem dibagi menjadi dua, kebutuhan fungsional dan kebutuhan nonfungsional.

\section{a) Analisis Kebutuhan Fungsional}

Analisis kebutuhan fungsional adalah pernyataan layanan yang harus diberikan kepada sistem agar dapat melakukan keperilakuannya dalam bereaksi terhadap masukan tertentu dan pada situasi tertentu (Kosasi \& Kuway, 2012). Kebutuhan fungsional harus dapat mengilustrasikan secara jelas fungsi-fungsi dan fiturfitur yang ada pada sistem yang dikembangkan. Berikut ini adalah analisis kebutuhan fungsional dari sistem yang akan dibagngun :

\section{Petugas Kelurahan:}

a. Petugas kelurahan sebagai admin dapat melkukan login untuk dapat mengaksesdata warga, melihat rincian data warga, mengedit data warga, dan menghapus data warga.

b. Petugas kelurahan dapat mengelola informasi, menginputkan informasi, mengedit informasi, dan menghapus informasi.

c. Petugas kelurahan dapat juga mengelola surat keterangan tidak mampu dan mengelola ouput surat keterangan tidak mampu.

2. Ketua RT:
a. Ketua RT dapat melakukan Login untuk melihat surat yang diajukan oleh masyarakat
b. Ketua RT da[at menegecek surat dan meneruskanya ke admin / petugas kelurahan
3. Masyarakat
a. Masyarakat dapat melihat informasi tentang desa, pengumuman dan informasi untuk pengajuan surat
b. Masyarakat dapat login dan melakukan pengajuan surat.

\section{b) Analisis Kebutuhan Non-Fungsional}

Berbeda dengan analisa kebutuhan fungsional, analisis kebutuhan non-fungsional berisi tentang batasan layanan atau fungsi yang diberikan sistem (Kosasi \& Kuway, 2012). Kebutuhan non-fungsional ini mencakup hardware dan software yang digunakan. Berikut ini adalah analisis kebutuhan non-fungsional sistem informasi publik yang akan dikembangkan :

Hardware :

Laptop untuk pembangunan sistem dengan spesifikasi sebagai berikut:
a. Processor Intel Corei7 4870HQ CPU (2.50 GHz).
b. Memory RAM
c. Hardisk untuk penyimpanan data
d. LayarLCD 15 inch.
e. Printer untuk mencetak laporan

Software:

Perangkat lunak untuk pembangunan sistem yaitu :

a. Sistem Operasi Windows 7

b. Adobe Dreamweaver CS6

c. Apache web server dan MySql database.

\subsection{Perancangan Sistem}

Setelah dilakukan analisa kebutuhan makan selanjutnya kebutuhan yang telah didapatkan dibuat dalam bentuk rancangan agar mempermudah dalam membangun sistem. Rancangan sistem pada penelitian ini menggunakan use case diagram. Use case diagram atau diagram use case merupakan pemodelan untuk prilaku(behaviour) sistem informasi yang akan dibuat. Use case mendeskripsikan sebuah interaksi antara satu atau lebih aktor dengan sistem informasi yang akan dibuat (A. S. \& Salahudin, 2013). Pada Diagram ini akan mendeskripsikan apa yang akan dilakukan oleh sistem (Rulyana \& Borman, 2014). Dengan diagram use case ini dapat mendeskripsikan tipikal interaksi antara admin, ketua RT dan masyarakat. Use case diagram 
sistem informasi pelayanan publik dapat dilihat seperti pada gambar 2.

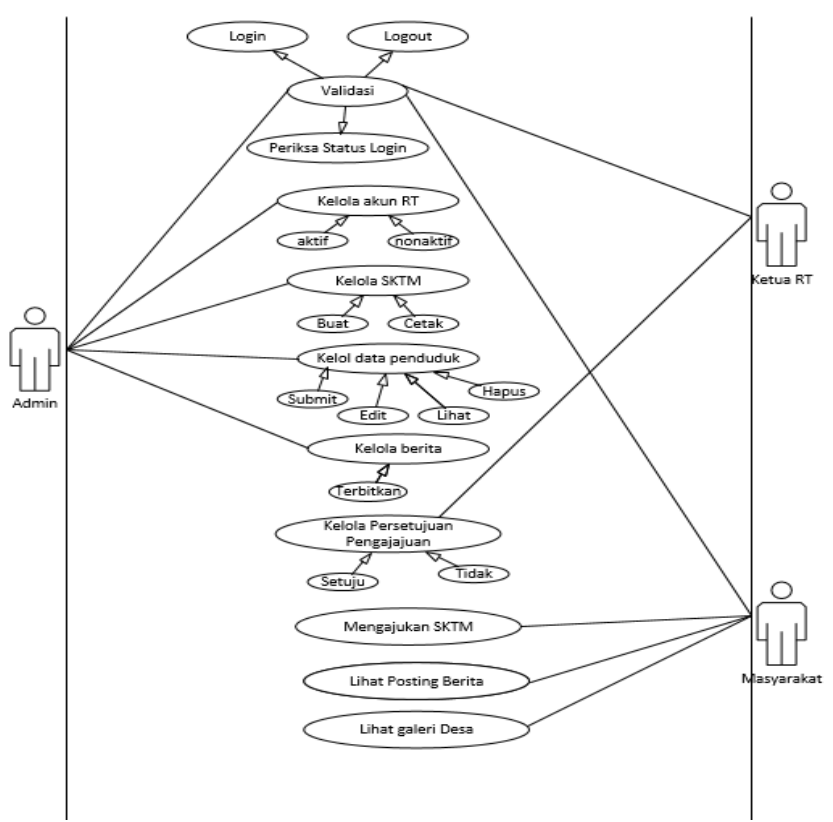

Gambar 2. Use Case Diagram Sistem Informasi Publik

\subsection{Implementasi (Coding)}

Coding atau pengkodean merupakan penerjemahan desain dalam bahasa yang bisa dikenali oleh komputer. Tampilan awal pada sistem informasi publik ini berupa menu utama yang berisi informasi tentang desa, seperti pada gambar 3 .

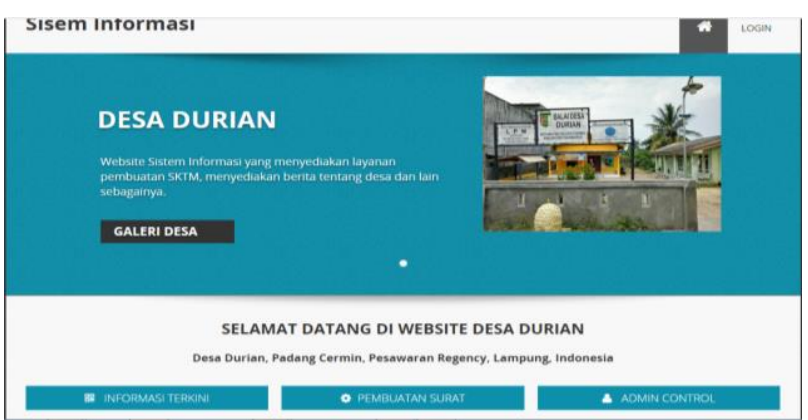

Gambar 3. Form Menu Utama Sistem Informasi Publik

Sistem informasi publik terdapat beberapa fitur utama diantaranya, menampilkan ifnormasi tentang desa, informasi tentang tata cara pengajuan surat, pengumuman, pengumuman penting dan programprogram yang sedang dilaksanakan. Di desa. Selain menampilkan informasi dan pengumuman-pengumuman penting tentang desa, sistem informasi publik ini terdapat fitur untuk mempermudah masyarkat membuat Surat Keterangan Tidak Mampu (SKTM) seperti pada gambar 4 berikut ini.

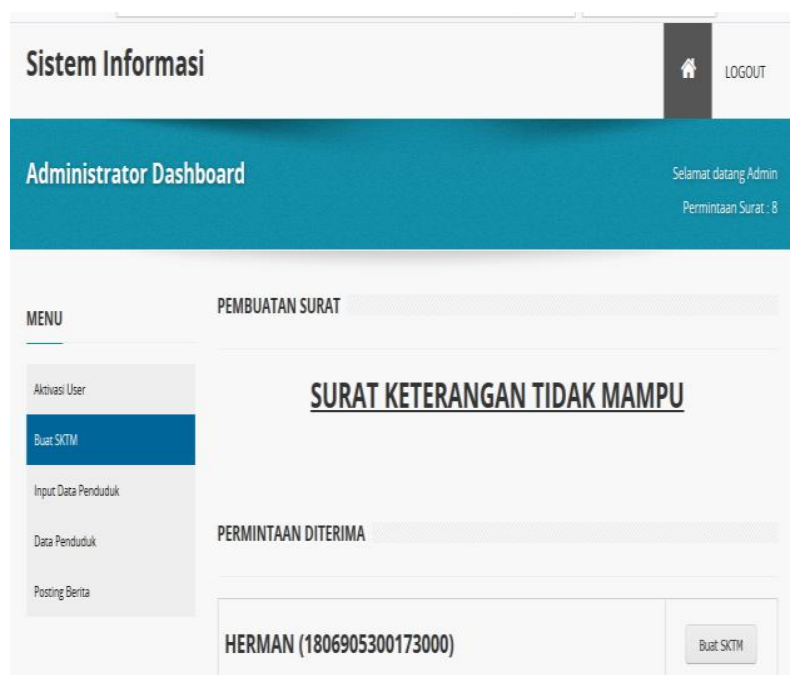

Gambar 4. Form Pembuatan Surat Keterangan Tidak Maтpu (SKTM)

Petugas Kelurahan/Kantor Desa dapat melihat informasi penduduk dan mengelola data penduduk yang ada di desa Durian mealuli fitur data penduduk, seperti pada gamabra 5 berikut ini.

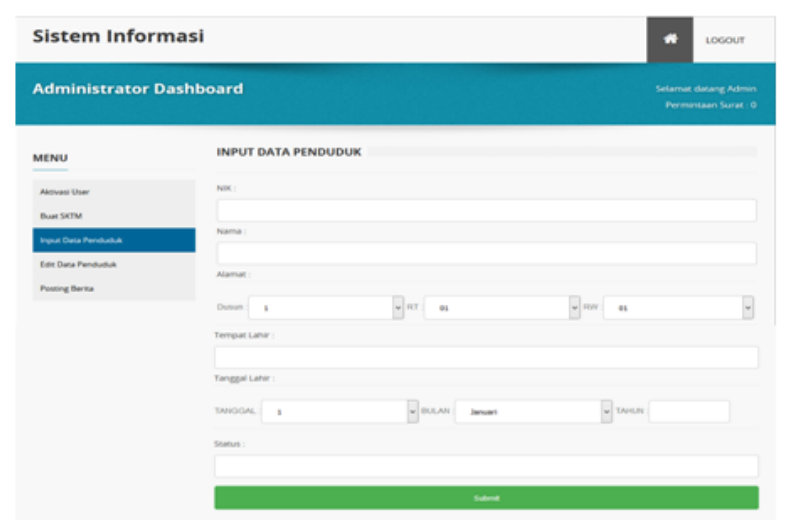

Gambar 5. Form Mengelola Data Penduduk

\subsection{Pengujian}

Pada tahapan pengujian digunakan metode pengujian black box testing, yaitu pengujian dari sisi fungsionalitas. Black box testing merupakan pengujian yang sistemnya tanpa memperhatikan struktur logika internal perangkat lunak (Arnova \& Ahmad, 2015). Pada dasarnya black box testing untuk mengetahui apakah perangkat lunak telah berfungsi dengan benar. Setiap fungsi pada sistem informasi publik ini di uji coba apakah dapat berfungsi dengan baik atau tidak. Berikut ini hasil dari pengujian yang telah dilakukan.

Tabel 1. Hasil Pengujian Black Box Testing

\begin{tabular}{|l|l|c|}
\hline \multicolumn{1}{|c|}{ Kelas Uji } & \multicolumn{1}{c|}{ Butir Uji } & $\begin{array}{c}\text { Hasil } \\
\text { Pengujian }\end{array}$ \\
\hline Login Admin & Hak Akses & Berhasil \\
\hline Login User & Hak Akses & Berhasil \\
\hline Login warga & Hak Akses & Berhasil \\
\hline
\end{tabular}




\begin{tabular}{|l|l|c|}
\hline \multicolumn{1}{|c|}{ Kelas Uji } & \multicolumn{1}{|c|}{ Butir Uji } & \multicolumn{1}{c|}{$\begin{array}{c}\text { Hasil } \\
\text { Pengujian }\end{array}$} \\
\hline Galeri Desa & $\begin{array}{l}\text { Foto Kegiatan } \\
\text { Desa }\end{array}$ & Berhasil \\
\hline Aktvasi User & $\begin{array}{l}\text { Data warga dan } \\
\text { user }\end{array}$ & Berhasil \\
\hline Buat SKTM & $\begin{array}{l}\text { Pembuatan } \\
\text { SKTM }\end{array}$ & Berhasil \\
\hline $\begin{array}{l}\text { Input Data } \\
\text { Penduduk }\end{array}$ & $\begin{array}{l}\text { Pengisian Data } \\
\text { Penduduk }\end{array}$ & Berhasil \\
\hline $\begin{array}{l}\text { Edit Data } \\
\text { Penduduk }\end{array}$ & $\begin{array}{l}\text { Mengedit dat } \\
\text { penduduk }\end{array}$ & Berhasil \\
\hline Posting Berita & $\begin{array}{l}\text { Pengisian } \\
\text { informasi berita }\end{array}$ & Berhasil \\
\hline
\end{tabular}

Rahmawati. (2013). Peran Brainwaire Dalam Sistem Informasi Manajemen. Jurnal Computech \& Bisnis , 7 No. 1.

Rulyana, D., \& Borman, R. I. (2014). Aplikasi Simulasi Tes Potensi Akademik Berbasis Mobile Platform Android. Seminar Nasional FMIPA-Universitas Terbuka. DKI Jakarta.

Simarmata, J. (2010). Rekayasa Perangkat Lunak. Yogyakarta: Andi Offset.

Sommervile, I. (2011). Software Engineering Ninth Edition. Addison-Wesley.

\subsection{Maintenance}

Setelah sistem informasi publik sudah digunakan maka butuh berbagai tindakan yang dilakukan untuk menjaga sistem agar berjalan dengan baik, seperti update fitur sistem dan instal antivirus pada komputer yang digunakan agar kinerja sistem tidak terganggu.

\section{Kesimpulan}

Berdasarkan penelitian yang telah dilakukan dalam membangun sistem informasi publik melalui beberapa tahapan diantaranya identifikasi masalah, analisa kebutuhan, mendesain sistem, implementasi sistem, pengujian sistem dan maintenance sistem. Sistem informasi publik ini terdapat fitur utama yaitu menampilkan informasi menampilkan ifnormasi tentang desa, informasi tentang tata cara pengajuan surat, pengumuman, pengumuman penting dan programprogram yang sedang dilaksanakan serta pembuatan surat yang dibutuhkan masyarakat seperti Surat Keterangan Tidak Mampu (SKTM).

\section{Daftar Pustaka}

A. S., R., \& Salahudin, M. (2013). Modul Pembelajaran Rekayasa Perangkat Lunak ( Terstruktur dan Berorientasi Objek). Bandung: Informatika.

Arnova, T., \& Ahmad, I. (2015). Sistem Informasi EDocument Korespodensi Pada Korem 043/Gatam. Jurnal Rekayasa dan Manajemen Sistem Informasi , 1 (2), 15-18.

Kosasi, S., \& Kuway, S. M. (2012). Studi Analisis Persyaratan Kebutuhan Sistem Dalam Menghasilkan Perangkat Lunak Yang Berkualitas. Jurnal Ilmiah SISFOTENIKA, 2, No. 1.

Lipursari, A. (2012). Peran Sistem Informasi Manajemen (SIM) Dalam Pengambilan Keputusan. JURNAL STIE SEMARANG , 05 No. 1, 26-37.

Pasolong, H. (2010). Teori Administrasi Publik. Bandung: Alfabeta. 